\title{
El financiamiento externo privado de las economías de APEC
}

DOI: $10.32870 /$ mycp.v4i14.144

Geneviève Marchini***

$\mathrm{E}$ 1 análisis de los sistemas financieros internos de los miembros de APEC, efectuado en una entrega anterior ${ }^{1}$, permitió recalcar los diferentes grados de desarrollo financiero de las economías y, por lo tanto, las variaciones nacionales en la capacidad de financiar el desarrollo económico sobre bases internas. En el presente artículo se busca complementar tal análisis abordando los aspectos internacionales del financiamiento de las economías de APEC. ¿Cuál es la participación de las economías de APEC en los mercados financieros globales? ¿Qué tipo de instrumentos es utilizado por los diferentes grupos de economías? ¿Cómo ha ido evolucionando el financiamiento de origen externo a lo largo de las dos últimas décadas del siglo XX?

La participación de economías de diferentes niveles de desarrollo en los mercados financieros internacionales, así como la evolución en las modalidades de financiamiento internacional, están estrechamente vinculadas con las transformaciones que se produjeron desde inicios de los 80 en la esfera financiera global. Para ello, en una primera sección se presentarán, sucintamente, las dos etapas de conformación de una esfera financiera global. En una segunda sección, se abordará la modalidad más "antigua" de financiamiento externo, es decir la concesión de créditos bancarios por parte de la banca internacional. En las secciones tercera y cuarta, se analizarán, respectivamente, el financiamiento aportado por los mercados internacionales de títulos negociables y la Inversión Extranjera Directa (IED). En la conclusión, se resumen los hallazgos principales del trabajo.

* Investigadora del Departamento de Estudios del Pacífico de la Universidad de Guadalajara.

** Agradezco la eficiente colaboración de Cristina Sánchez Rocha en la elaboración de los cuadros.

\section{Las etapas del surgimiento de la esfera financiera global}

El surgimiento de la actual esfera financiera global se efectuó en dos etapas: a una integración indirecta a través de los euromercados siguió una fase de integración directa de los mercados nacionales. La globalización financiera, entendida como proceso de conformación de una esfera financiera unificada a través de "interconexiones muy estrechas entre los sistemas monetarios y los mercados financieros nacionales" (Chesnais, $1996^{a}$ ) es producto de las políticas de dereglamentación y de liberalización aplicadas por las economías industrializadas desde la segunda mitad de los 70 . Materialmente descansa en la incorporación de los avances realizados en materia de tecnología de la información y telecomunicaciones (Castells, 1999).

La primera etapa de integración financiera indirecta (1960-1979) se dio en el contexto de mercados financieros nacionales segmentados, todavía sometidos a reglamentos y controles de capitales introducidos después de la crisis de los 30 y durante la segunda guerra mundial. El mercado del eurodólar, que nació en Londres en los 50, cobró importancia en la década siguiente, desarrollándose a un ritmo exponencial desde 1973-1974, cuando intermedió una fracción sustancial (estimada en $30 \%$ del total), (Bourguinat, 1995a) de los excedentes de los exportadores petroleros. De manera prácticamente simultánea, el colapso del sistema de tipos de cambio fijos (1973), que llevó a la flotación de las principales monedas, inauguró un período de amplias fluctuaciones en el valor de las divisas e hizo entrar el mercado cambiario en la era globalizada (Chesnais, $1996^{a}$ ), estimulándose paralelamente el desarrollo de los primeros derivados financieros.

El mercado interbancario de las 
eurodivisas se extendió posteriormente hacia Europa, y luego hacia otros continentes, mediante la creación de plazas offshore, como las de Singapur y Hong Kong en Asia, a la vez que incorporaba nuevas divisas internacionales y nuevas instituciones participantes. Este mercado dereglamentado ${ }^{2}$ funcionaba al margen de las esferas financieras nacionales, aún cuando permitía, a las instituciones que operaban en estos ámbitos, realizar ciertos "arbitrajes reglamentarios" a través de filiales offshore. De este modo, la dinámica de esta primera fase de integración financiera se centró alrededor de la banca internacional y de sus créditos sindicados, creándose, desde 1973 hasta inicios de los 80, una "economía internacional de endeudamiento", caracterizada por una elasticidad casi infinita de la oferta de fondos para un nivel dado de tasas de interés (Bourguinat, 1995b), y un costo real de los fondos a menudo negativo (en razón de la inflación).

Esta abundancia de recursos facilitó una primera participación de las economías en desarrollo en el mercado financiero internacional en calidad de prestatarios. Los préstamos permitieron financiar crecientes déficits en cuenta corriente y fomentaron temporalmente un mayor crecimiento económico, así como una mayor demanda de parte de estos países, la cual vino a sostener las exportaciones manufactureras de las economías desarrolladas.

La crisis de la deuda que estalló en 1982 señaló la transición hacia una nueva dinámica en el proceso de integración financiera internacional. En efecto, el cambio en la política monetaria estadounidense (1979) y el movimiento de dereglamentación aplicado en el sistema financiero más desarrollado del mundo iniciaron la transición hacia una "economía de mercados financieros" en la cual los acreedores llevan la batuta: la considerable demanda de fondos de esta economía reorientó los flujos mundiales hacia el financiamiento de los "déficits gemelos" de las finanzas públicas y de la cuenta corriente. Con la excepción de las economías asiáticas de crecimiento rápido, la mayoría de gobiernos y empresas de las economías en desarrollo dejaron de ser sujetos de crédito internacional.

Tres procesos han vuelto posible esta nueva configuración de la esfera financiera internacional: la apertura de los mercados, la dereglamentación y la desintermediación (Bourguinat, 1995 ${ }^{\mathrm{a}}$ ). Partiendo de los Estados Unidos y de Gran Bretaña a inicios de los 80, las medidas que permiten su despliegue han ido adoptándose de manera paulatina en los demás países industrializados. La apertura de los diferentes compartimentos de los mercados requirió el levantamiento de los controles de capitales entre economías nacionales y, al interior de éstas, la abolición o la suavización de las barreras legales que separaban las actividades de los diferentes tipos de intermediarios (como el Glass-Steagall Act en Estados Unidos). La dereglamentación levantó el marco restrictivo de las finanzas administradas (controles de tasas de interés y de comisiones, orientación y control cuantitativo del crédito, obligaciones de reservas legales) a la vez que autorizó la multiplicación de las innovaciones financieras suscitadas por la mayor volatilidad de tasas de interés y tipos de cambio. Finalmente, el desarrollo de la titularización y del financiamiento directo produjo la desintermediación, es decir el retroceso relativo de la intermediación bancaria tradicional. Del lado de la captación, los bancos se hallaron en competencia con los inversionistas institucionales: fondos de pensiones, fondos de inversión y aseguradoras, cuya expansión constituye una de las característica salientes de la nueva etapa de integración financiera internacional. Del lado de los activos, la banca enfrentó la competencia de los mercados, que ofrecen a sus mejores clientes empresariales la posibilidad de financiarse a menor costo, colocando sus propios títulos negociables.

Los mercados de títulos de deuda pública de las economías de la OCDE, y en primer lugar los de Estados Unidos, han desempeñado un papel destacado en la consolidación de esta nueva fase de integración financiera internacional. La creación, el desarrollo y/o la apertura a la inversión extranjera de los 
mercados secundarios de papeles gubernamentales permitieron a los gobiernos financiar sus considerables déficits fiscales a la vez que mantenían políticas monetarias restrictivas, orientadas a lograr la estabilidad del nivel de precios. Simultáneamente, se satisfacía la creciente demanda de títulos de los inversionistas institucionales.

La incorporación de los "mercados emergentes" de las economías de desarrollo intermedio, a inicios de los 90, constituyó la última etapa del proceso de integración financiera internacional. Esta etapa ha sido marcada, en mayor grado que las anteriores, por la frecuencia de las crisis financieras con repercusiones regionales 0 mundiales; desde la crisis mexicana (1994) hasta la crisis en Argentina (2001), pasando por la crisis asiática (1997) y sus corolarios en Rusia (1998) y en Brasil (1999), podemos deducir que estos episodios subrayan el carácter todavía precario de esta integración financiera internacional de los mercados emergentes.

Ahora bien, esta incorporación sólo fue posible debido a la transformación de la esfera financiera de estos países, emprendida durante la década anterior de exclusión de los mercados financieros internacionales: estimulada por las consecuencias nefastas de la crisis de 1982, la adopción de nuevos modelos de desarrollo orientados hacia afuera y de medidas de liberalización financiera interna, constituyó una condición necesaria de la segunda fase de integración internacional de las economías de desarrollo medio. Por otro lado, la apertura a la IED dinamizaba estos flujos.

Al finalizar el siglo XX, las economías de diferentes niveles de desarrollo gozaban de grados de integración diferenciada en la esfera financiera global. Las economías de desarrollo alto o intermedio accedían a una gran diversidad de financiamiento externo, sea a través de créditos bancarios, de la colocación de instrumentos negociables o de la captación de IED, a la vez que invertían en el exterior. En el otro extremo, las economías más pobres tenían un acceso muy restringido al financiamiento externo, esencialmente mediante la captación de IED o la concesión de créditos bancarios ${ }^{3}$.

\section{El crédito de la banca internacional}

El crédito bancario ha sido históricamente la primera modalidad liberalizada de financiamiento externo, caracterís-tica de la primera fase de crecimiento de una esfera financiera global. Las estadísticas presentadas en el cuadro 1 muestran la evolución de los créditos consolidados de la banca internacional otorgados a las economías de APEC desde mediados de los 80 hasta el año 2000. Este tipo de financiamiento presenta algunos rasgos sobresalientes que lo diferencian de otras modalidades que veremos a continuación. En primer lugar, cabe subrayar que todas las economías de APEC recurren a él. Una segunda característica sobresaliente se relaciona con los montos en juego, que son masivos pero que han tendido a crecer de manera lenta durante el período, con algunos momentos de estancamiento -1988-89 y 1998y de aceleración -1986-87 y 1993-94.

Por otro lado, las economías de APEC han recibido una proporción creciente del crédito internacional vigente, pues su participación se elevó de $42.25 \%$ del total en 1985 a $59 \%$ en 1994 , decreciendo luego de la crisis asiática para alcanzar $45 \%$ del total en $1998^{4}$. Ahora bien, cuáles son las economías que incrementaron su participación en el acervo de crédito a lo largo del período considerado? Entre 1985 y 1998, tanto Hong Kong como Singapur participaron 


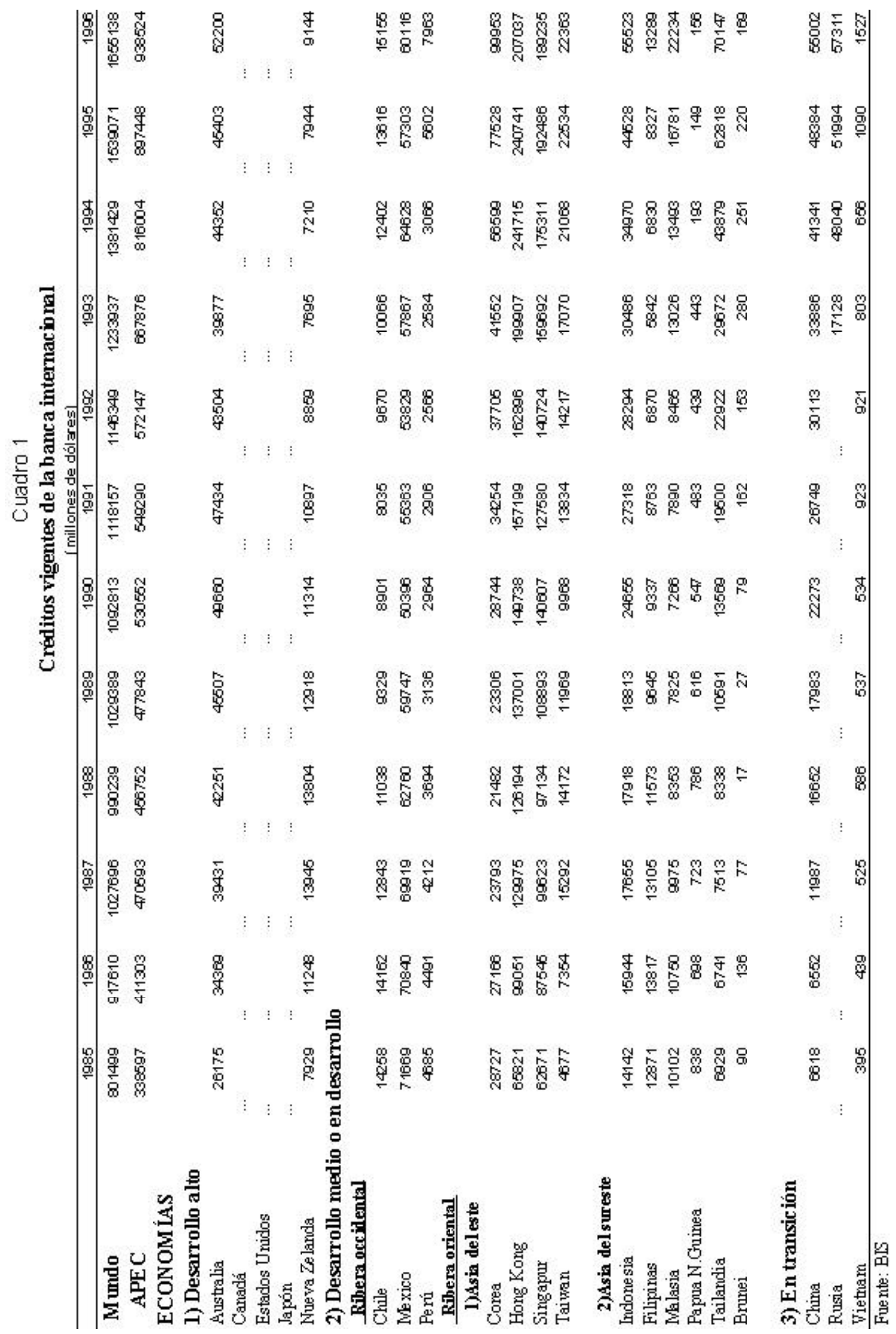


en promedio del $20 \%$ en los créditos vigentes de las economías de APEC, una característica que se relaciona con su papel de centros financieros regionales ${ }^{5}$. Australia, México y Corea del Sur por un lado, así como China y Rusia en la segunda mitad del período, figuran entre los principales receptores de créditos internacionales, con proporciones comprendidas en promedio entre 5 y $10 \%$ del crédito agregado vigente de las economías de APEC.

Por otro lado, durante los 80 y al final de los 90, después de las sucesivas crisis financieras (crisis de la deuda de 1982, crisis mexicana de 1994, crisis asiática de 1997), la banca internacional disminuyó en términos relativos, y a veces absolutos, su exposición hacia las economías en desarrollo, en especial México (21\% del crédito total de las economías de APEC en 1985, con 71669 millones de dólares, contra 50396 millones en $1990-9.4 \%$ del total-, y 63 643 en 2000), y Chile, pero también Corea del Sur y Tailandia (99 953 y 70147 millones de dólares respectivamente en 1996, 58773 y 26 646 millones en 2000). La recuperación de la condición de sujeto de crédito internacional, que había sido más rápida para las economías asiáticas que para las latinoamericanas, generalizándose en la segunda mitad de los 90 , retrocedió netamente luego de la crisis asiática, afectando a todas las economías en desarrollo.

En 1999, la incorporación de datos referidos a Canadá, Estados Unidos y Japón permite tener una visión más exacta de la magnitud relativa de los fondos recibidos por las diferentes economías. En 1999 y 2000, Estados Unidos concentró respectivamente $44 \%$ y $50 \%$ de todo el acervo de crédito vigente de la banca internacional con agentes pertenecientes a economías de APEC, a la vez que Japón respondía por 16 y $19 \%$. La participación total de las economías de nivel de desarrollo alto alcanzaba más de $65 \%$ en 2000 y por el contrario, las economías de menor nivel de desarrollo, como Perú, Filipinas, Papua-Nueva Guinea y Vietnam no daban cuenta de más de $2 \%$ de los créditos. Una fracción importante de esta deuda estaba contratada a corto plazo; al respecto, NuevaZelanda, Perú, Singapur y Taiwán presentaban los mayores porcentajes de deuda de corto plazo (superiores a 60\% del total), mientras Brunei, Papua y Rusia mostraban una composición de la deuda más orientada hacia plazos mayores.

Finalmente, ¿cuáles fueron los agentes internos que más recurrieron al crédito internacional? El cuadro 2 muestra situaciones contrastadas. Por un lado, en los casos de Singapur, Japón, China, Canadá, Australia y Corea del Sur, es el sector bancario el que se halla mayormente en el origen del endeudamiento externo con la banca internacional, mientras que por otro lado, en Estados Unidos, Chile, México, Perú, Indonesia, Filipinas, Malasia, Papua, Tailandia y Vietnam, son las empresas no-financieras las que más contratan crédito externo. Por último sólo en Brunei (80\%), y en menor medida en México (24\%), el sector público está en el origen de una fracción sustancial del crédito externo contratado.

\section{El financiamiento a través de emisiones internacionales de títulos negociables}

El carácter más reciente de este tipo de financiamiento externo, en especial para las economías de nivel de desarrollo medio o bajo, se refleja en los datos disponibles que abarcan solamente los años que van desde 1993 al 2000. El financiamiento obtenido por las economías mediante la emisión de títulos de deuda y su colocación en los mercados internacionales es, de manera predominante, de mediano y largo plazo, pues los montos vigentes en los mercados de bonos y notas alcanzaban, en 20006049.7 miles de millones de dólares, contra sólo 333.8 miles de millones para los instrumentos de corto plazo de los mercados de dinero (véanse cuadros 3 y 4$)$.

Ahora bien, el ritmo de crecimiento anual de ambos tipos de mercados ha sido elevado, en especial hacia el final del período, cuando alcanzó más de $30 \%$ para los mercados de dinero y alrededor de $20 \%$ para los mercados de bonos y notas. Si consideramos ahora los flujos de corto plazo recibidos por las economías de APEC, aparece claramente el efecto de las crisis 
Cuadro 2

Crédito internacionales por agente receptor interno

(marzo 2001)

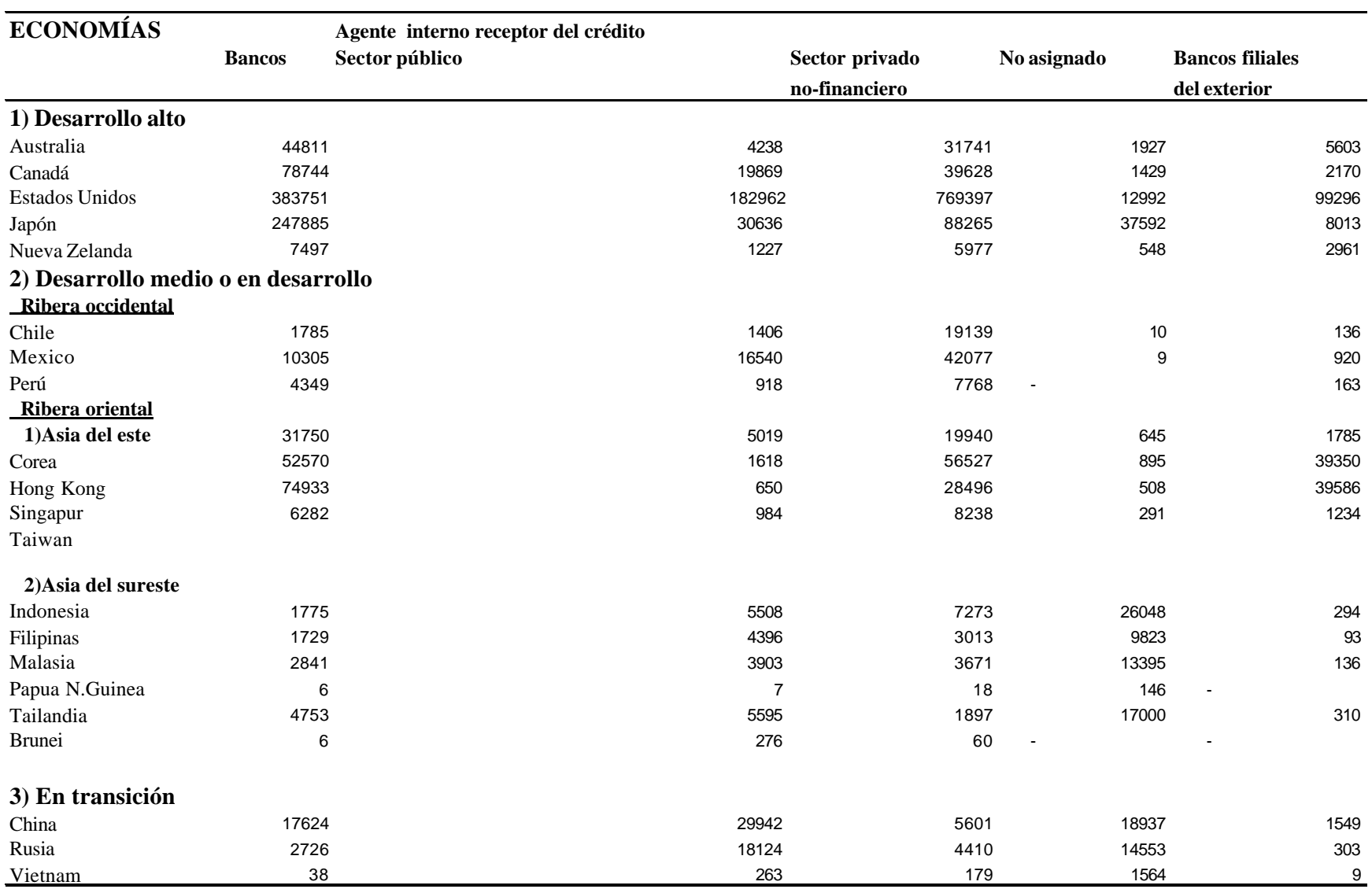

Fuente: BIS

sufridas por las economías de desarrollo medio, que se tradujeron en tasas de crecimiento significativamente más bajas que el promedio mundial, en 1994-1995, después de la crisis mexicana, y en 1997-1999, siguiendo a la crisis asiática. Por el contrario, las consecuencias de estas crisis sobre los flujos provenientes de los mercados de bonos han sido menos obvias. Finalmente, se puede observar que el acceso de las diferentes economías a estos mercados ha sido muy diferenciado: los países de menor nivel de desarrollo relativo tienen un acceso restringido. Así, Perú, Brunei, Papua y Vietnam no participan en los mercados de bonos, mientras que sólo acceden permanentemente a los mercados de dinero las economías de nivel de desarrollo alto y algunas economías de nivel de desarrollo medio: México, Corea del Sur, Hong Kong, Tailandia y, hacia el final del período, Indonesia y Filipinas.
Un análisis más detallado del cuadro 3 permite observar que la mayor parte del financiamiento proveniente de emisiones de bonos y notas en los mercados internacionales ha sido dirigido hacia las economías de mayor nivel de desarrollo de APEC. A lo largo del período 1993-2000, Australia, Canadá, Estados Unidos, Japón y Nueva-Zelanda han concentrado, en conjunto, alrededor de $92 \%$ del financiamiento recibido, mientras México y Corea del Sur recibían cada uno proporciones que fueron variando entre 1.5 y $4 \%$ del total, y los demás países, por lo general, menos del $1 \%$ del total.

Ahora bien, un cambio de importancia mayúscula se ha producido en la magnitud de los fondos recibidos por los países desarrollados: a inicios del periodo Japón era el primer receptor, con $43 \%$ de los fondos totales, seguido 
Cuadro 3

Bonos y notas internacionales

Montos vigentes a fin de período en miles de millones de dólares

\begin{tabular}{|c|c|c|c|c|c|c|c|c|}
\hline & 1993 & 1994 & 1995 & 1996 & 1997 & 1998 & 1999 & 2000 \\
\hline Mundo & 1915 & 2277.3 & 2571 & 2953 & 3307.9 & 4102.5 & 5111.2 & 6049.7 \\
\hline APEC & 753.6 & 848.3 & 929.3 & 1109.4 & 1310.5 & 1658.4 & 2184.2 & 2572.1 \\
\hline \multicolumn{9}{|c|}{ |ECONOMÍAS } \\
\hline \multicolumn{9}{|c|}{ 1) Desarrollo alto } \\
\hline Australia & 47.8 & 61.7 & 66.4 & 77.2 & 74.2 & 79.2 & 89.6 & 97 \\
\hline Canadá & 144.5 & 161.8 & 171.9 & 175.7 & 178.4 & 202.6 & 215.9 & 203.7 \\
\hline Estados Unidos & 160.3 & 185.1 & 242.2 & 368.7 & 531 & 823 & 1291.7 & 1727.3 \\
\hline Japón & 326.1 & 337.2 & 334.6 & 323.1 & 304.5 & 313 & 331.8 & 280.5 \\
\hline Nueva Zelanda & 10 & 9.4 & 8.7 & 7.6 & 7.7 & 7.6 & 7.1 & 7 \\
\hline
\end{tabular}

2) Desarrollo medio o en desarrollo

Ribera occidental

Chile

Mexico

0.8

0.7

0.7

2.3

4

4.7

6.6

7.2

Perú

28.5

41.1

49.2

52.2

60.9

63.7

Ribera oriental

1)Asia del este

\begin{tabular}{|c|c|c|c|c|c|c|c|c|}
\hline Corea & 14.7 & 19.2 & 25.1 & 38.7 & 50.7 & 52.3 & 49 & 49.1 \\
\hline Hong Kong & 5.8 & 11.7 & 12.3 & 14.4 & 21.6 & 20.2 & 24.1 & 28.5 \\
\hline Singapur & 0.6 & 0.7 & 1 & 3.2 & 4.7 & 5.6 & 6.8 & 10.3 \\
\hline Taiwan & 0.4 & 2.2 & 2.6 & 3.7 & 6.3 & 7.4 & 7.3 & 7 \\
\hline \multicolumn{9}{|c|}{ 2)Asia del sureste } \\
\hline Indonesia & 2.4 & 4.3 & 4.4 & 10.4 & 16.3 & 16.1 & 12.8 & 1 \\
\hline Filipinas & 1.2 & 2.4 & 3 & 6.4 & 9.4 & 10.1 & 14.2 & 15.5 \\
\hline Malasia & 4.9 & 5.4 & 6.9 & 9.4 & 12.5 & 12 & 14.1 & 15.2 \\
\hline \multicolumn{9}{|c|}{ Papua N.Guinea } \\
\hline Tailandia & 3.2 & 5.8 & 7.1 & 12.3 & 14.4 & 14.4 & 15.1 & 13.8 \\
\hline \multicolumn{9}{|l|}{ Brunei } \\
\hline \multicolumn{9}{|c|}{ 3) En transición } \\
\hline China & 8.4 & 12.9 & 12.8 & 13.9 & 17.4 & 17.6 & 17.9 & 17.6 \\
\hline Rusia & 1.7 & 1.8 & 1.1 & 1.3 & 8.2 & 20.4 & 19.3 & 17.7 \\
\hline Vietnam & 1.7 & & & & & & & \\
\hline
\end{tabular}

Fuente: BIS

por Estados Unidos, con $21 \%$ y Canadá con $19 \%$; al final, las proporciones obtenidas por cada uno de estos tres países se había modificado radicalmente: en 2000 , Estados Unidos concentraba alrededor de $67 \%$ de los fondos recibidos por las economías de APEC, mientras la participación de Japón había caído al $11 \%$ y la de Canadá a menos de $8 \%$. Ahora bien, la revisión de las cifras absolutas nos muestra que esta evolución no es debida a una disminución de las emisiones japonesas o canadienses en los mercados internacionales de bonos, sino a un alza desmesurada de las emisiones estadounidenses, que fueron multiplicadas por 10 entre diciembre de 1993 (160.3 miles de millones de dólares) y diciembre de 2000 (1727.3 miles de millones de dólares). 
Cuadro 4

Instrumentos en los mercados de dinero internacionales montos vigentes a fin de périodo en miles de millones de dólares

\begin{tabular}{|c|c|c|c|c|c|c|c|c|}
\hline & 1993 & 1994 & 1995 & 1996 & 1997 & 1998 & 1999 & 2000 \\
\hline Mundo & 108.5 & 113.5 & 132.5 & 162.3 & 175.1 & 186.1 & 249.5 & 333.8 \\
\hline APEC & 55.8 & 53.8 & 54 & 61.1 & 55.5 & 54.4 & 56.8 & 76.3 \\
\hline \multicolumn{9}{|c|}{ |ECONOMÍAS } \\
\hline \multicolumn{9}{|c|}{ 1) Desarrollo alto } \\
\hline Australia & 17 & 11.9 & 13.6 & 13.3 & 10.9 & 11.2 & 13.1 & 16 \\
\hline Canadá & 1.9 & 1.3 & 1.5 & 2.7 & 4.2 & 5.2 & 5.1 & 5.2 \\
\hline Estados Unidos & 15 & 17.7 & 18.7 & 17.3 & 19.7 & 23.3 & 24.1 & 37.2 \\
\hline Japón & 10.1 & 11.8 & 12.3 & 16.4 & 12.2 & 6.6 & 6 & 6.9 \\
\hline Nueva Zelanda & 0.7 & 1 & 1 & 1.7 & 2.9 & 2.7 & 3.5 & 4.3 \\
\hline
\end{tabular}

2) Desarrollo medio o en desarrollo

Ribera occidental

Chile

Mexico

$9.9 \quad 8.7$

3.1

2.5

1.5

0.9

1.8

2.8

Perú

$\underline{\text { Ribera oriental }}$

1)Asia del este

Corea

Hong Kong

0.2

0.2

2.3

\section{9}

0.5

$\begin{array}{ll}0.7 & 0.7\end{array}$

0.6

Singapur

0.2

0.8

0.9

1.2

1.8

1.9

2.5

Taiwan

2)Asia del sureste

Indonesia

Filipinas

Malasia

Papua N.Guinea

Tailandia

Brunei

0.1

0.2

0.3

0.3

0.1

0.1

0.1

\section{3) En transición}

China

Rusia

Vietnam

Fuente: BIS

En lo que concierne a las economías de menor nivel de desarrollo, México, Corea del Sur y Hong-Kong muestran incrementos sostenidos de los montos concertados ${ }^{6}$. Es también el caso, más tardíamente y en menor medida, de Singapur, Taiwán, Indonesia, Filipinas, Tailandia, China y Rusia. Ahora bien, a partir de 1998 se nota un estancamiento de las emisiones vigentes de bonos de la mayoría de estas economías, lo que da cuenta de la mayor aversión al riesgo por parte de los inversionistas, que provocó tanto un encarecimiento como una mayor escasez de fondos disponibles para emisiones de alto riesgo.

Los mercados de dinero muestran tendencias cercanas pero menos extremas que las que acabamos de presentar. En 1993 cuatro economías concentraban más de $92 \%$ de los fondos captados: Australia, con 30\% del total, 
Estados Unidos con 26\%, Japón y México, con cerca de $18 \%$ cada uno. Después de 1994 la participación de México disminuyó drásticamente, tanto en valores absolutos como en términos relativos, en respuesta a la crisis experimentada por el país; un fenómeno similar se produjo en el caso de Japón, a partir de 1998. Por el contrario, Estados Unidos aumentó su peso relativo y absoluto hasta llegar a captar algo menos de la mitad de los fondos orientados hacia las economías de APEC en 2000. Sin alcanzar cifras como las mexicanas, la participación de otras economías de APEC, como Corea del Sur y Tailandia, se expandió hasta 1996, para luego caer. Solamente Hong Kong muestra una presencia que ha ido creciendo paulatinamente durante todo el periodo.

En síntesis, la capacidad de captar fondos a través de los mercados internacionales de títulos negociables está restringida a las economías más desarrolladas de APEC. Las desigualdades entre economías son apabullantes y se han ampliado a lo largo del periodo: en 2000, Estados Unidos concentraba $66 \%$ de los fondos captados en estos mercados por las economías de APEC, y $27.6 \%$ del total mundial, mientras Japón captaba, respectivamente, alrededor de $11 \%$ y de $4.5 \%$. Sólo algunas economías de desarrollo medio o bajo accedían a este tipo de financiamiento y su participación se estancó o cayó después de las crisis mexicana y asiática.

\section{El financiamiento a través de la IED}

El cuadro 5 nos muestra la evolución de la IED neta desde 1982 hasta 1999. Durante todo el período, Estados Unidos ha sido claramente la mayor fuente y el mayor receptor de IED: de 1982 a 1990, y de nuevo, en 1998-99, se volvió el mayor receptor neto. Por el contrario, Japón ha sido exportador neto durante todo el periodo, y llegó a ser la primera fuente de inversión directa, con excepción de algunos años durante los cuales Estados Unidos se volvió exportador neto. A diferencia de Estados Unidos, la inversión directa recibida por Japón ha sido muy reducida hasta 1997, cuando empezó a esbozarse un cambio. Por otro lado, como lo espera la teoría económica, las economías en desarrollo fueron prácticamente todas receptoras netas de IED? Corea del Sur constituye una excepción, pues se volvió crecientemente inversionista directa neta hasta 1998, cuando las reestructuraciones productivas desencadenadas por la crisis asiática vuelven a esta economía, al igual que la japonesa, atractiva para la IED. Dentro del grupo de economías en desarrollo, China ha sido, desde 1993, el mayor receptor de IED neta en valor absoluto, con 36978 millones de dólares en 1999, seguida desde 1994 por México, con 11 786 millones de dólares en 1999.

Ahora bien, los datos de flujos brutos, que presentan tanto las inversiones realizadas por las economías en otros países, como las inversiones que éstas reciben en su propio territorio, muestran una elevación progresiva tanto de los flujos de inversión directa que "salen" de las economías como de los flujos que "entran" , lo cual evidencia una intensificación de los flujos de inversión directa en ambos sentidos, particularmente notable desde mediados de los 90 .

\section{Conclusión}

Este texto ha introducido el tema general de las principales fuentes de financiamiento externo privado de las economías de APEC. Tanto las formas de financiamiento como los montos recibidos han ido modificándose a lo largo de los años. El crédito bancario y la IED constituyen formas de financiamiento externo asequible para la totalidad de las economías, aún para las de nivel de desarrollo bajo, mientras el financiamiento mediante la emisión y colocación internacional de títulos de deuda aparece reservada a las economía de mayor nivel de desarrollo relativo.

El crédito bancario, que constituía la modalidad predominante en los 80 , ha ido cediendo importancia a otras formas de financiamiento, sea mediante emisiones de títulos negociables en los mercados internacionales, sea a través de la recepción de IED. Al final del periodo la exposición agregada de la banca internacional hacia economías en desarrollo ha ido disminuyendo rápidamente; 
Cuadro 5

I nversion extranjera directa neta

\begin{tabular}{|c|c|c|c|c|c|c|c|c|c|c|c|c|c|c|c|}
\hline 1984 & 1985 & 1986 & 1987 & 1988 & 1989 & 1990 & 1991 & 1992 & 1993 & 1994 & 1995 & 1996 & 1997 & 1998 & 1999 \\
\hline-1032 & 184 & 2009 & 149 & 1859 & 4682 & 6407 & 2703 & 151 & 2376 & 2184 & 8399 & -760 & 1459 & 2921 & 9676 \\
\hline 1091 & -2507 & -655 & 994 & -150 & 757 & 2352 & -2963 & 1230 & -962 & -1079 & -2171 & -3472 & -10763 & -9364 & 7287 \\
\hline 12410 & 5950 & 16620 & 29860 & 41090 & 30900 & 17970 & -9370 & -25080 & -32590 & -34050 & -40970 & -5380 & 1020 & 40270 & 124640 \\
\hline-5970 & -5850 & -14440 & -19140 & -35940 & -47060 & -48720 & -30330 & -14630 & -13710 & -17180 & -22470 & -23240 & -22860 & -21350 & -9960 \\
\hline 841 & 957 & 622 & 849 & 1344 & -269 & 141 & 600 & 2900 & 1074 & 818 & 3995 & 3765 & 2669 & -7 & 0 \\
\hline 67 & 142 & 313 & 885 & 952 & 1277 & 653 & 696 & 540 & 600 & 1672 & 2205 & 3446 & 3354 & 1840 & 4366 \\
\hline 1542 & 1984 & 2036 & 1184 & 2011 & 2785 & 2549 & 4742 & 4393 & 4389 & 10973 & 9526 & 9186 & 12831 & 11312 & 11786 \\
\hline-89 & 1 & 22 & 32 & 26 & 59 & 41 & -7 & 136 & 687 & 3108 & 2048 & 3242 & 1696 & 1881 & 1969 \\
\hline 58 & -357 & -767 & 101 & 371 & 520 & -268 & -309 & -434 & -751 & -1651 & -1776 & -2345 & -1605 & 666 & 5135 \\
\hline$\ldots$ & $\ldots$ & $\cdots$ & $\ldots$ & $\ldots$ & $\cdots$ & $\ldots$ & $\ldots$ & $\cdots$ & $\ldots$ & $\ldots$ & $\ldots$ & $\ldots$ & $\ldots$ & $\ldots$ & $\cdots$ \\
\hline 1210 & 809 & 1529 & 2630 & 3537 & 2005 & 3541 & 4361 & 887 & 2534 & 3973 & 925 & 2049 & -773 & 7018 & 3041 \\
\hline 222 & 310 & 258 & 385 & 576 & 682 & 1093 & 1482 & 1777 & 1648 & 1500 & 3743 & 5594 & 4499 & -400 & -2817 \\
\hline 9 & 12 & 127 & 307 & 936 & 563 & 530 & 544 & 228 & 864 & 1289 & 1079 & 1335 & 1086 & 2127 & 632 \\
\hline 797 & 695 & 489 & 423 & 719 & 1668 & 2332 & 3998 & 5183 & 5006 & 4342 & 4178 & 5078 & 5137 & 2163 & 1553 \\
\hline 113.4 & 82.4 & 99.5 & 115.4 & 119.7 & 221.3 & 155.4 & 202.5 & 293.6 & 62,0 & 57,0 & 454,6 & 111,3 & 28,6 & 109,6 & 296,5 \\
\hline 400 & 162 & 262 & 182 & 1081 & 1726 & 2304 & 1847 & 1966 & 1571 & 873 & 1182 & 1405 & 3315 & 7185 & 5867 \\
\hline 1124 & 1030 & 1425 & 1669 & 2344 & 2613 & 2657 & 3453 & 7156 & 23115 & 31787 & 33849 & 38066 & 41674 & 41117 & 36978 \\
\hline 0 & 0 & 0 & 0 & 0 & 0 & 0 & 0 & 0 & 0 & 589 & 1708 & 1809 & 2260 & 1739 & 1165 \\
\hline
\end{tabular}

Fuente: FMI, ADB.

con la excepción de las economías de la ribera occidental de la Cuenca y de Malasia, los flujos netos de crédito recibidos entre 1999 y 2000 por las economías en desarrollo o en transición fueron negativos. Por el contrario, su exposición hacia Estados Unidos ha ido incrementándose en casi 246 billones de dólares.

Una tendencia similar se observa en los mercados de títulos negociables, pues la predominancia de Estados Unidos en la captación de fondos mediante emisiones de bonos, notas y papeles de corto plazo ha ido creciendo desde la crisis asiática. Como resultado de ello, Estados Unidos concentraba, en $2000,66 \%$ del acervo total de fondos, y recibió por este concepto, entre 1999 y 2000 , un flujo neto cercano a 450 billones de dólares. Mientras tanto, las economías asiáticas amortizaban deuda en términos netos -43 billones para Japón, 6 y 5 billones respectivamente para Corea del Sur y China. Finalmente, en el caso de la IED, Estados Unidos volvió a ser receptor neto a finales de los 80, pasando al primer lugar en valor absoluto delante de China. En otras palabras, la economía más grande de APEC ha ido incrementando su captación de recursos después de la crisis asiática y recibe ahora fondos en proporciones muy elevadas, retomando de esta manera el papel que desempeñaba a inicios de los 80 .

\section{Referencias bibliográficas}

Bourguinat, Henri (1995a): Finance internationale, 2d ed., Ed. PUF, Paris.

Bourguinat, Henri (1995b): La tyrannie des marchés- Essai sur l'économie virtuelle, Ed. Economica, Paris.

Castells, Manuel (1999): La era de la información economía, sociedad, cultura, Ed. Siglo XXI, México, vol. 1. Chesnais, François (ed) (1996): La mondialisation financière: genèse, coûts, enjeux, Ed. Syros, Paris.

Chesnais, François (1996a): "Introduction générale", in Chesnais, François (ed) (1996) La mondialisation financière: genèse, coûts, enjeux, Ed. Syros, Paris

\section{Fuentes de datos estadísticos}

FMI (2001): Estadísticas financieras internacionales. BIS (2001): información estadística en línea, en http:// www.bis.org 


\section{Notas}

1 Geneviéve Marchini: "Las estructuras financieras domésticas de las economías de APEC. Bancos y mercaods financieros (1980-1999)", México y la Cuenca del Pacífico, vol. 4, n | 13, mayo-agosto de 2001, p. 2437.

$2 \mathrm{Al}$ efectuarse las transacciones en monedas que no eran de curso legal en el país en el cual operaba el banco, éstas no eran sujetas a las tasas de interés administradas ni a las obligaciones de reserva legal aplicables a las operaciones en moneda nacional, y escapaban a la supervisión de las autoridades locales

3 A partir de 1999, la serie agrega datos para economías desarrolladas para las cuales no se registraba previamente información. En el caso de las economías pertenecientes a APEC, se agregan Canadá, Estados Unidos y Japón. Por esta razón, las cifras de créditos agregados antes de esta fecha no son comparables con los datos de años posteriores.

4 Recordamos que el cambio en el modo de cálculo de la serie vuelve difícil una comparación entre años anteriores y 1999-2000.
5 La participación relativa de Hong Kong culmina con cerca de $30 \%$ del total en 1994.

6 Las emisiones vigentes de Corea del Sur muestran un estancamiento a partir de 1997, mientras el crecimiento de las emisiones de México no se ve mayormente afectado por la crisis de 1994-1995.

7 Taiwán y Hong Kong, que son también inversionistas directos en países de la región, no presentan estadísticas. Singapur es también un inversionista directo importante, con montos exportados que superan las inversiones coreanas, pero siguió recibiendo IED en montos aún superiores, con lo cual siguió siendo importador neto de IED.

8 Japón constituye una excepción en la medida en que sus flujos mayores, en tanto inversionista fuera del país, se produjeron entre 1988 y 1990, es decir antes de su crisis financiera interna; En este país, una intensificación de la IED recibida solo se produjo a finales de los 90 . 